\title{
V. Proposal for constructing, and putting in its place, an iron tunnel under the river Thames
}

\section{Colonel Lennox}

To cite this article: Colonel Lennox (1810) V. Proposal for constructing, and putting in its place, an iron tunnel under the river Thames, Philosophical Magazine Series 1, 36:147, 34-39, DOI: 10.1080/14786441008563134

To link to this article: http://dx.doi.org/10.1080/14786441008563134

曲 Published online: 18 May 2009.

Submit your article to this journal $\sqsubset \pi$

Џ Article views: 2

Q View related articles $\square$ 
The magnesia was precipitated by caustic potash : it weighed, after desiccation, 16 grains.

$9^{\circ}$. The oxides of iron and manganese were dissolved in an excess of muriatic acid, and pouring, by little and little, saturated carbonate of potash into the dissolution until red floccules were visible, and then leaving it to repose 24 hours, all the carbonate of iron precipitated, whilst that of the manganese remained in the liquor.

The cartonate of iron, after calcination, gave 24 grains of oxide : and that of manganese, deposited by ebullition, by the same operation, only $1 \frac{1}{3}$-Which makes in all :-

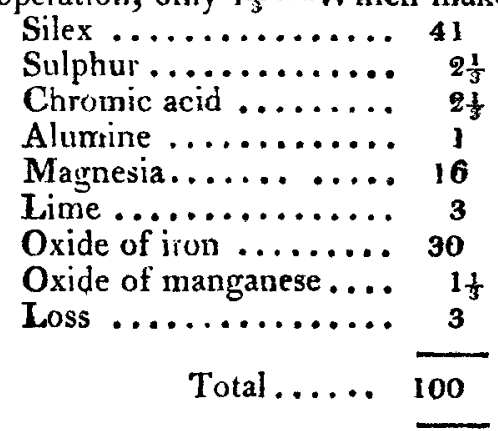

Analysis of the metallic iron isolated by the magnetic needle. $1^{\circ}$. 100 parts of this stone gave 28 of 'metallic iron, which is very brittle, owing to the nickel it contains. $2^{\circ}$. 40 grains of this iron were dissolved in nitro-muriatic acid, and by means of ammonia in excess the oxide of iron was separated, which weighed 45 grains. The dissolution of nickel in this alkali was evaporated to siccity to expell all the ammonia. The oxide of nickel was redissolved by muriatic acid, and precipitated by the prussiate of potash, which gave one grain of the prussiate of nickel. We may infer, from these physical characters, and results of chemical analysis, that this stone is like all other meteoric stones hitherto known.

V. Propasal for constructing, and putting in its Place, an Iron Tunnel under the River Thames. By Colonet Lennox.

To Mr. Tilloch.

SIR, I nerkwith send you a plan for a tunnel under the Thames, which I hope you will not deem unworthy of a place in your valuable Magazine. 
Being informed that no particular plan has yet been determined on by the Thames Tunnel Company*, they are extremely welcome to adopt this if they think fit. I cannot avoid encouraging a hope, that it will be found practicable : but, should my partiality render me too sanguine in favour of it, as the idea, $I$ believe, is new, the publication of it may lead to some other of more ingenuity, and which may be easier and safer in the execution.

Explanation of a plan for constructing a tumnel of castiron under the river Thames :-

Fig. 1. A A, (Plate II.) section across the river. The waving line shows the present depth of the river; $a$, the additional depth required by the plan.

Fig. 2. B B B, three of the frames of which it is proposed that the whole tunnel shall be formed: they are to be of cast-iron, each of one piece, and to be joined together by the flanches $d d d$, which are all one foot broad and four inckes thick, with the screws $e e e$, in figs. 2 and 4 , of four inches diameter, with half-inch sheet-lead between :-or the joints may be secured with the cement employed by steam-engine builders.

Fig. 3. CC, section of the tunnel, showing the above three frames, in figs. 2 , in perspective; each frame to be ten feet in length, eighteen feet wide inside, and twelve feet high at the sides; the top to be convex, rising two feet in the middle; to be four inches thick at the bottom and sides, and three at top. Each frame will weigh upwards of forty tons + .

Fig. 4. DD D, elevation of the same frames, which shows the screws that unite the exterior flanches, and also the iron cramps, $f f$, which embrace the two adjoining flanches at botiom; these cramps to be each twelve inches broad, six inches thick, and two feet high.

Fig. 3. $g g$, tubes of eight inches bore, with openings to receive leakage water, and to convey it to one of the ends to be pumped out.

$i$ ii, screw-holes. The dotted line $k k$ expresses the paving when the whole is completed.

* I believe the Thames Tunnel Company bave settled the plan they mean to follow; but as the ideas suggested by Col. Lennox may prove useful on some future occasion, 1 have given it a place in this number.-Eorr.

+ Should the carriage of pieces of this weight from the foundry be found impracticable, the sides, and top and bottom, may be cast in separate pieces, with flanches to join them, at the corners. In this case the joinings of the different parts may be so disposed that no two of the transverse joinings shall coincide, which will give additional strength to the whole, as every joint may thus be supported with three solid pieces at that place in which
ji falls. 
By the scction across the river it appears that the deptli of the bed at low water (being only about 30 feet) is not sufficient to admit of laying down a tunnel snch as $I$ propose upon the bottom, without obstructing the course of the streain, or interfering with the ease of navigation: therefore, the first thing necessary would be, to excavate the bed of the river entirely across to abont 16 feet deeper, and from 60 to 80 feet wide; and to render it as even as possible throughhout; which I conceive may be effected without extraordinary labour or difficulty. This being done as far as from $b$ to $c$, fig. 1 , about 800 feet or something more, $I$ will next suppose eighty of those frames, previously formed agreeably to the plan and section, figs. 2 and $\beta$, to be joined by screwing them strongly together, as represented in figs. 2 and 4 , with half-inch sheet-lead between the flanches; which operation should be performed on the bank of the river rather below the level of low water, in a situation where the tide may have free access to it.

If then the ends of these 80 tunnel-frames so joined be (when empty) close stopped with strong oak plank, and well secured so as to render them perfectly water-tight, $a$ machine is formed which on the admission of the tide will float; as may be proved by the subjoined calculation, which for greater security does not include the convexity of the top. At spring-tide, therefore, the whole may be floated to the required sitnation, and by additional weights applied sunk in its proper place. But in case of any irregularity in its descent, or unevenness of the bottom prepared to receive it, ly removing those additional weights it will again become liunyant, when the necessary remedies may be applied and obstacles removed. When once properly placed, by turning cocks fixed in each end it will soun fill with water and be permanently bedded.

Calculation of the weight of this tunnel in round numbers :-

Cast-iron .. 20,020 cubic feet.... about 4,270 tons.

Lead..... $\quad 566 \ldots \ldots \ldots \ldots \ldots . \quad 178$

Oak ..... $\quad 200 \ldots \ldots \ldots \ldots \ldots \ldots \quad 5$

Tnns .. 4,453

Water displaced 1,850,000 cubic feet ... 5,162

This tunnel will require to sink it more than 709

Exclusive of the convexity at top estimated at 60

$$
\text { Total.. } 769
$$


With respect to the manner of sinking this machine, I propose that two short ropes of sufficient strength, with loops at each ent, should be passed over each frame, and sightly secured to keep them in their places; that when the machine is floated to its destined situation, (which should be about an hour before low water at the lowest tide,) anchors and cables shall be in readiness to secure it in its place; and that then a number of boats (suppose 160) shall attend, half on one side and half on the other, each with five tons of ballast conveniently disposed so as immediately to hook on to the ends of the short ropes before mentioned, in such a inanner that one end of the tunnel shall not sink before the other, but both exactly together. These weights may be so regulated as occasion may require, should there appear any irregularity in its descent; and when it is placed as desired, and water admitted to fill it, they may be removed altogether*. The whole of this operation may, I am persuaded, be effected in two hours, that preceding and that following elbb-tide, if every previous arrangement be properly made.

This part of the tunnel is then supposed to eccupy the space irom $b$ to $c$, fig. 1 , and to be piaced so as that the upper surface of it shall be nearly equal to, or rather below, the present bottom represented by the waving line. After which, by piling off the tide from low-water mark, the ends may be finished, as on dry land; which may be done either by a continuation of the same frames, or by arches of masnnry or of brickwork, as may be judged best. It will then only rdmain to open the communication with the middle part, by removing the oak planking at each end, and pumping out the water; when, by laying a sufficient quantity of ballast so as to form a road-way clear above the lower flanches, and restoring the banks to their former state, the tunnel will be immediately ready for use.

In the execution of this project a situation should be selected close to low-water mark, of nearly 300 yards in length, where it would be necessary to lay down blocks of sufficient strength to support the great weight, and upon which the whole 80 frames may be screwed together, the level of which should be at least 15 feet below that of spring tides to ensure its floating when cumpleted.

It may be objected to this great machine, that from its

* Or parhaps the sinking may be conveniently effected by mercly admitting from 800 to 1000 tons of water into the tunnel, a pump of sufficient power being properly secured in each end frame to puinp out 200 ar 30) !cas, should it be found accessary to fluat the tunucl again. 
vast weight and great length, the power of 67 screws at each joining would be inadequate to hold the whole perfectly together; and that in case of accident the whole must be infallibly lost, as it would then be impossible to remove it from the spot on which it would immediately sink, or even to separate the different parts of it. But as the tumnel formed in the manner proposed will be subjected to no particular force whatsoever at its launching, but be altogether equally horne up by the rising tide; as the weights necessary to sink it may be all so gradually applied as to ensure its regular descent, to which the form of the whole when joined as above, viz. convex at the top and rising at the ends, together with the greater thickness of the metal at the bottom, are circumstances particularly tavourable; and as from the nature of the bottom it is sure to rest on a soft and uniform bed of sand, on which it cannot meet with any object to occasion any partial bearing,-I conceive the danger of accident is very remote, and the strength of the entire sufficiently secured: besides, trials may be made in a safe situation.

The chief difficulty appears to me to be the excavation of the bed of the river to the depth required. The best morle of effecting this, or whether it would not be better to choose another situation in which the existing depth might be found sufficient, I leave to more able and experienced engineers to determine; stating merely, that as the materials of which the tunnel is to be composed can be procured for about $£ 44,000$; allowing fifty per cent. additional for all other charges incuried in its execution, I do not conceive the expense would exceed the sum of E6,000.

I beg leave further to add, that if it should be desired to enlarge this tunnel so as to afford a foot-path in addition to the space allowed for two carriages to pass, I conceive it may safely be-done by giving it six more feet in width, making altogether 24 feet between the interior flanches; and in order to afford it still greater strength, I would in this case omit the interior lateral flanches, and in the room thereof, apply plates of cast-iron of three or four inches thick, the full height of the sides, to extend from the middle of one frame to that of the next, to be fastened by a number of the same kind of screws to the sides of the two adjoinıng frames, with sheet-lead between and completely covering the joint inside. This would give the tunnel great additional strength without much increasing its weight, besides that it would leave nearly a foot more of 
free space inside; the increase of expense on this account would not, I suppose, much exceed twelve or fifteen thousand pounds, in addition to that before-stated.

$$
\text { I am, sir, }
$$

Your obedient humble servant,

Bath, June 1810.

iV. Caulfield Lennox.

VI. Six Theorems, containing the chicf Properties of all Regular Douzeave Systems of Music; with Twelve Corollaries thence deduced, showing ot thers of their Relations ; and Thirteen Scholia, containing the Temperaments of as many Systems, calculated thereby. With Remarks. By $M r$. John FAREY.

\section{To Mr. Tilloch.}

SIR, I am much pleased to observe, that at length a beginning has been made, at publishing tables of the Beats in 15"; made by the 72 concords in different systems of Musical Temperament, by your new correspondent $\mathrm{Mr}$. C. J. Smyth, of Norwich, in your last Number, who will, I hope, persevere, and give us tables of many other systems, accompanied by such critical remarks, on their comparative merits and defects in practice, as he appears well qualified to make, either in your Magazine, or in the separate work which he has announced on the subject.

Some time ago, I had thoughts of preparing a work on Harmonics, perhaps as a kind of supplement to Dr.-Robert Smith's justly celebrated work ; but the prospect being now rather distant, of my being able to find leisure to complete this design, I am induced by the above paper of Mr.Smyth's, and the publication of a small work on Harmonics, by $\mathrm{Mr}$. J. Marsh of Chichester, to transcribe from my papers some Theorems, showing the properties of regular douzeaves, or of such systems of twelve notes in the octave, as have all their fifths alike tempered, except, that between $\mathrm{G}$ and $b \mathrm{E}$, when there is a bearing fifth or quint wolf: but first I beg to make a few remarks.

In douzeaves, or systems of twelve nntes, there are generally 16 wolves or tempered concords, differing * from

* Wolves, taken in their general sense, are not always larger than the temperaments, but may be equal to them, as happens throughout the isotonic or equal temperament scale, and may ever be less than their respective temperaments, in some cases, as in scholia 1 and $7:$ they are, in fact, the places in the douzeave 6 other defective scales, where the resulting intervals or unavoidable inequalities fall, and, as such, are very importane to be known and attended to by the composers of music, to be performed in such scales. 